InVisible Culture • Issue 33: After Douglas Crimp

\title{
After Douglas Crimp \\ Questionnaire Response: \\ Juliane Rebentisch
}

\section{Juliane Rebentisch}

Published on: Jan 05, 2022

DOI: $10.47761 / 494 \mathrm{a} 02 \mathrm{ff} 6.9749 \mathrm{ffc} 1$

License: Creative Commons Attribution 4.0 International License (CC-BY 4.0). 
His voice

Douglas Crimp (1944-2019)

One of the last conversations I had with Douglas touched on the question of one's own voice in a public text. It was not about one's own voice in the sense that is audible from any writing-even there, sometimes especially there, where authors try to neutralize theirs. It was about one's own voice as a personal one, about moments in which one's own experience is not only an implicit horizon for what one writes but becomes a public stake itself. For much of Douglas's writing is characterized by a structure in which the personal, the personal anecdote, is not a mere adjunct to the argument but its very point of departure.

"Mourning and Militancy" (1989), one of Douglas's most famous public interventions during the AIDS crisis, was the first text in which he made a personal story the starting point for his reflections. The very moving recollection of how the suppressed grief over the death of his own father shifted into a symptom stands at the beginning of a plea for the political recognition of psychological conflict. In a climate of despair over the AIDS deaths, mourning did not seem an appropriate response to many activists at the time. They demanded of themselves and others to turn their grief into anger-as if this could be done without much ado-and take to the streets to fight against a cynical politics that treated the epidemic as a natural disaster against which nothing could be done. Douglas's intervention in this context was by no means a simple defense of a work of mourning, mostly imagined as individual and private, against the collectively experienced pressure to act. Rather, he was concerned with a rejection of the dichotomy of politics and the psyche itself. In this way, he unraveled the knots of the social and the psychic that inhibited the movement precisely because they remained obscured by the opposition of society and psyche, outside and inside. With the mixture of factual unreservedness and argumentative caution characteristic of Douglas's activist texts in general, he made reactions such as guilt, shame, and autoaggression among the survivors (with and against Freud) readable as forms of a displaced grief over the loss not only of an unbearable number of people, but of an entire way of life. And, at the same time, addressable in their social dimension as the psychic life of power. The courage to put one's own experience on the line publicly, and from there to address difficult issues in order to bring them into a common space and make them discussable, was certainly one of the reasons why Douglas became one of the most important, literally life-saving voices, during the AIDS crisis. 
It is no accident that "Mourning and Militancy" was one of the last texts Douglas published in October magazine. For the proximity that his intellectuality sought to the dimension of experience was to remain determinative of his attitude toward authorship. In contrast to the conventions of academic writing, this critical stance, reflecting on its own situatedness, certainly claimed a methodological queerness. Its power can be seen in his writings that put art history into perspective politically as well as in terms of cultural theory; for example, in his works on Warhol. In "Mario Montez, for Shame" (1999) Douglas gives an almost tenderly precise reading of Warhol's Screen Test \#2, in which he turns the painful experience of shame into the vanishing point of a queer politics that is directed not least against the normalizing tendencies of the gay and lesbian movement centered as it is around the concept of pride. The experience of being afflicted by the shaming of another person is explained as a confrontation with one's own vulnerability, which, precisely because it is experienced as absolutely personal, points to the community of all those who are rejected and shamed by the norm. As in "Getting the Warhol We Deserve" (1999), Warhol is placed in a perspective that resolutely ties art history back to the eminently political question of what history is written for whom and to what end.

The principle that relates the supposed neutrality of art history to the present from which it becomes readable is given another twist in Before Pictures (2016), the last book published during Douglas's lifetime. This is a memoir of sorts, though Douglas has judiciously avoided flagging the book as such. Judiciously, because the book is about the connection between experience and theory from the other side. The fragmentary narratives of his own life are interspersed with long passages of art critical, art historical, and art theoretical reflection. The result is a book that re-reads the entire art history of late modernism through ostensibly personally motivated constellations of the 1960s and 1970s: the U.S. Minimalist scene encounters the Playhouse of the Ridiculous in Max's Kansas City; Charles James, the cult figure of U.S. fashion, casts a shadow of his drapery on the works of Daniel Buren at the Guggenheim in 1971; Gordon Matta Clark's architectural interventions provide a backdrop for the cruising culture on the piers of New York documented by Alvin Baltrop; the enthusiasm for Agnes Martin accompanies the conversion of a dandyesque hippie look to the gay "clone style" of Levis 501s and T-shirts; there are transitions between 1970s disco culture, roller skates, body building, and Divine; the reading of Jacques Derrida (undertaken with Craig Owens) mediates attendance at George Balanchine's ballet. Through these and other constellations the book enables a noncanonical understanding of late modernism and its transgressions into aesthetic 
postmodernism, for which Douglas, especially through his immensely influential exhibition Pictures (Artists Space, 1977) and the accompanying text of the same name, has also become a central reference.

The prehistory of his theory of postmodernism exposes the biographical coincidences that made this theory possible and chronicles the searches made on the way to authorship. At the end of the introductory chapter, for example, there is a remark about how writing about women artists helped the young gay art critic to find his own voice. All of this is done, however, in a way that refuses any self-historicizing closure of his work. The constellations laid out do not coalesce into a narrative; they remain fragmentary and keep themselves open for possible follow-up discussions. In addition, the book also contains self-critical comments on older texts. Some take the form of a correction of factual errors, while others take the form of a distancing of older arguments or judgments on the basis of entirely new readings of the objects in question. The book thus bears witness not only to what it means to live with works of art as an art critic, but also to the lives of the works of art themselves, lives that are revealed in the histories of their multiple interpretations. In this regard, Douglas quotes Louise Lawler, who states that "the work works in the process of its reception." This is true of works of art, but also, though in a different way, of theoretical or critical texts, and Before Pictures bears witness to this as well. It is a strength of the book, another manifestation of the author's ethical commitment to the connection between theory and experience, that even where his own reception is at stake-as in the case of his famous essay "Pictures"- he presents himself as one voice among many. Explicitly, he recognizes and embraces that his text has developed a history he never thought of when he put it together in the late 1970s.

In all these texts by the author "Douglas Crimp," there is a generosity and a trust in the openness and seriousness of his readers that has made him vulnerable, and has created strong connections; many friendships have been formed among those who loved "Douglas Crimp"/Douglas Crimp. In fact, it is hardly possible to read his texts without being touched by the intimacy that underpins them, that is, without letting the reading itself become personal. One cannot help but relate them to one's own experience, thus engaging in a movement of thought in which the public and the private, the general and the particular, slide into one another in such a way as to challenge the sense of both. I was certainly not saying anything new to Douglas when I expressed once again how much I admire his writing in this regard. No one could accept compliments like he could, in a way that generously expanded communicative space. In the acceptance of the compliment there was always an acknowledgement 
and sincere interest in the other person, and any compliment was therefore allowed to be more than a courtesy; a move in a conversation that could develop effortlessly in all directions, and shift between registers. It was incredibly impressive how he also managed to include illness and preparation for his own death in these conversations. Once again, he was able to share the difficult, and keep this existential process discussable in both its painful and sad, as well as surreal and even funny, parts. In other words, to turn it into an object of intellectual curiosity in such a way that it could become part of a lived, and therein very lively, story of friendship. This was a gift, and it remains a comfort and an inspiration-like the work of a person for whom intellectuality and conduct of life came together in a way that suggests a queer appropriation of the term "authentic."

Juliane Rebentisch is Professor of Philosophy and Aesthetics at Hochschule für Gestaltung Offenbach/Main. She is a member of the Research Counsil at the Institute for Social Research in Frankfurt/Main and a Regular Visiting Professor of the German Department at Princeton University.

This is an English translation of an obituary originally published in German, in the journal TEXTE ZUR KUNST.

Juliane Rebentisch, “DOUGLAS CRIMP (1944-2019),” TEXTE ZUR KUNST, EVIL, no. 116 (December 2019): 226.

$\underline{\text { Click here to return to the other questionnaire responses. }}$ 